\section{A Continuously Ventilated Natural- light Growth Chamber Complex for Greenhouse Environmental Studies}

\author{
Jack W. Buxton \\ Department of Horticulture and Landscape Architecture, University of \\ Kentucky, Lexington, KY 40546
}

\author{
John N. Walker \\ Department of Agricultural Engineering, University of Kentucky, \\ Lexington, $K Y 40546$
}

Additional index words. controlled environments, carbon dioxide, high-intensity discharge lighting

\begin{abstract}
Natural-light growth chambers constructed within a greenhouse compartment were equipped with a ventilation/circulation system, two stages of heating, and evaporative cooling. Air drawn from the greenhouse compartment continuously ventilated the chambers; the air was heated or cooled to the set-point temperature. A computer-controlled environmental system maintained uniform temperatures within the chambers and maintained the temperature within $\pm 1 \mathrm{C}$ of the set point at night and during periods of low solar radiation; during higher solar radiation periods, control was not as precise. Carbon dioxide concentration was accurately maintained, and the photosynthetic photon flux from supplemental high-pressure sodium lamps was $\approx 200$ $\mu \mathrm{mol} \cdot \mathrm{m}^{-2} \cdot \mathrm{s}^{-1}$. The natural-light growth chambers provide a means for studying the interactive effects of temperature, light, and other environmental variables in experiments to increase production efficiency.
\end{abstract}

Most institutional research greenhouses are partitioned into independently controlled compartments. Typically, the area of each compartment ranges from 55 to $80 \mathrm{~m}^{2}$. The compartments are adequate for research when components of the environment, such as temperature and $\mathrm{CO}_{2}$, remain constant. However, the study of environmental factors, either independently or in factorial designs, requires many separate compartments. As a result, experiments frequently are conducted with few treatments and/or replications. Even with an adequate number of compartments, the variability between and within compartments may be large. Also, the size of the compartments is excessive for many greenhouse research projects. For these reasons, researchers constructed small naturallight growth chambers or stand-alone minigreenhouses for greenhouse environmental

Received for publication 24 Sept. 1990. The investigation reported in this paper (90-10-188) is in connection with a project of the Kentucky Agr. Expt. Sta. and is published with approval of the Director. We appreciate the assistance of Donna Switzer, Darrell Slone, and Lloyd Dunn. The cost of publishing this paper was defrayed in part by the payment of page charges. Under postal regulations, this paper therefore must be hereby marked advertisement solely to indicate this fact. studies (Buxton et al., 1985; Eng et al., 1983; Ewen et al., 1980; Hoffman and Rawlins, 1970; Morse and Evans, 1962; Mortensen, 1982; Phene et al., 1978, 1979). The small chambers provided a more uniform and accurately controlled environment than was possible in larger greenhouse compartments. bench.

${ }^{2}$ Distance from back left corner of growth chamber.

yShadow from temperature sensor.
Chambers built within greenhouses were less expensive to construct than mini-greenhouses and provided better control of the environment, since the greenhouse served as a buffer to extreme changes in temperature outside the greenhouse. However, light intensity was slightly less in chambers built within greenhouses, but the natural daylength and light quality approximated that of a single-layer glasshouse.

Most natural-light growth chambers use a closed air circulation system. To achieve the set-point temperature, the internal air was heated or cooled (Hoffman and Rawlins, 1970; Morse and Evans, 1962; Mortensen, 1982; Phene et al., 1978) and a minimum amount of ventilation replenished the $\mathrm{CO}_{2}$. Other environmental control systems provided cooling by ventilating continuously with outside air; the recirculated air was heated to achieve higher temperatures (Buxton et al., 1985; Ewen et al., 1980). Thermostats controlled the environment in some systems (Buxton et al., 1985; Eng et al., 1983; Morse and Evans, 1962; Mortensen, 1982), whereas computers controlled the environment in others (Hoffman and Rawlins, 1970; Phene et al., 1978, 1979). The continuously ventilated system is a simpler and less expensive system to construct than the closed system. In contrast to a closed system, the continuously ventilated system does not require refrigeration nor an elaborate air recirculation system for each growth chamber. Also continuous monitoring of $\mathrm{CO}_{2}$ and its injection into the environment is not required. The desired $\mathrm{CO}_{2}$ concentration is controlled by adjusting the ratio between the $\mathrm{CO}_{2}$ flow rate and the flow rate of the ventilated air. This paper describes the design and performance

Table 1. Light intensity at bench height from a 1000-W HPS lamp suspended $135 \mathrm{~cm}$ above the

\begin{tabular}{|c|c|c|c|c|c|c|c|}
\hline \multirow[b]{3}{*}{ Distance $(\mathrm{cm})^{\mathbf{z}}$} & \multicolumn{7}{|c|}{ Light intensity $\left(\mu \mathrm{mol} \cdot \mathrm{m}^{-2} \cdot \mathrm{s}^{-1}\right)$} \\
\hline & \multicolumn{7}{|c|}{ Distance $(\mathrm{cm})^{\mathrm{z}}$} \\
\hline & 20 & 40 & 60 & 75 & 90 & 110 & 130 \\
\hline & \multicolumn{7}{|c|}{ No reflective material } \\
\hline 20 & 162 & 181 & 223 & 236 & 234 & 219 & 186 \\
\hline 40 & 149 & 186 & 216 & 226 & 226 & 206 & 164 \\
\hline 60 & 150 & 185 & 209 & 185 & 208 & 188 & 157 \\
\hline 80 & 164 & 187 & $161^{y}$ & $155^{y}$ & 214 & 192 & 164 \\
\hline 100 & 180 & 187 & 227 & 237 & 226 & 204 & 171 \\
\hline \multirow[t]{2}{*}{120} & 182 & 198 & 234 & 249 & 257 & 232 & 205 \\
\hline & \multicolumn{7}{|c|}{ Reflective material around chamber } \\
\hline 20 & 215 & 245 & 278 & 288 & 285 & $271^{7}$ & 240 \\
\hline 40 & 203 & 238 & 260 & 268 & 270 & 248 & 213 \\
\hline 60 & 200 & 231 & 255 & 255 & 248 & 235 & 203 \\
\hline 80 & 212 & 233 & $204^{y}$ & $228^{y}$ & 261 & 242 & 212 \\
\hline 100 & 230 & 235 & 280 & 281 & 288 & 260 & 237 \\
\hline 120 & 255 & 272 & 300 & 312 & 316 & 292 & 268 \\
\hline
\end{tabular}






Fig. 1. View of natural-light growth chamber. (A) Electric control panel; (B) air exhaust tube and plastic duct; (C) temperature sensor box; (D) $\mathrm{CO}_{2}$ tank; (E) HID light fixture; (F) air flow meter.

of a computerized natural-light growth chamber continuously ventilated with air drawn from a greenhouse compartment.

Chamber design. Six chambers were constructed within a greenhouse compartment $(10.4 \times 7.8 \mathrm{~m})$. The greenhouse compartment was equipped with three $190-\mathrm{W}$ exhaust fans $(\approx 1.6$ air exchanges $/ \mathrm{min})$, a motorized air inlet vent, cross-fluted cellulose evaporative cooling pads, and perimeter hot-water heating. The chambers, $1.22 \times$ $1.53 \times 1.07 \mathrm{~m}\left(2 \mathrm{~m}^{3}\right)$, were constructed with acrylic (Figs. 1 and 2). Angle aluminum strengthened all corners, and all edges were sealed with silicon-based sealant. Eight wing bolts (two on each side, top and bottom) attached the door to the chamber; an airtight seal formed when the bolts were tightened to pull the door against a foam gasket around the door opening. A plywood base supported the chamber.

A galvanized metal air-intake chamber contained the evaporative-cooling system, consisting of the water reservoir, a submergible 1.1-amp pump, and a float valve. A $40-\mathrm{W}$ ventilation/circulation fan mounted to the side of the air-intake box provided about two air exchanges/min. Air entered the chamber through the air-intake box and flowed through a galvanized metal heating duct and flexible plastic tubing. Intake air entered the chamber through 14 holes drilled in a PVC pipe located along each side of the chamber (Fig. 2). The 14 holes, oriented $30^{\circ}$ to the front and back walls, directed the air upward along the walls and downward across the plants. In one chamber design, the air, after circulating through the chamber, flowed under the plexiglass platform (supporting the PVC pipe) back into the greenhouse (Fig. 2). In a second design, used for studies of $\mathrm{CO}_{2}$ concentration, the walls of the chamber sat flush on the plywood base. The air exited through a U-cm-diameter hole in the chamber side wall into the greenhouse compartment or the air was diverted through plastic ducts to the outside of the greenhouse and away from the greenhouse air intake (Fig. $1)$.

Two resistance coils attached to ceramic cones that screwed into a standard ceramic lamp socket provided two stages of heating
(Fig. 2). The resistance coils heated the air as it flowed through the metal heat duct before it entered the chamber. A rheostat, regulating the flow of electricity to the coils, provided for fine tuning of the swing in temperature above and below the set point. During the cooling mode, air moved through wet evaporative cooling pads. During the heating or ventilation mode, the evaporative pads remained dry. An electrical wiring diagram for the environmental control system is shown in Fig. 3.

Environmental control. A commercial greenhouse computer (Oglevee System II-AC; Connellsville, $\mathrm{Pa}$.) controlled the environmental equipment in the growth chambers and in the greenhouse compartment. An aspirated temperature module in the center of each chamber and in the greenhouse compartment sensed dry- and wet-bulb temperatures. A quantum light sensor mounted outside at the ridge of the greenhouse compartment detected light intensity. The greenhouse temperature set point was maintained below the set-point temperature of the coolest chamber. Chamber temperature was then raised to the treatment set point. By adjusting the time between addition or removal of heating stages and by setting limits, based on the rate of temperature increase or decrease, in the computer program, the computer maintained the set-point temperature.

Performance. To determine the uniformity of temperature within the growing area, shielded thermocouples were placed in three planes, 30, 45, and $60 \mathrm{~cm}$ above the chamber floor, with nine thermocouples spaced within each plane. The temperatures were measured day and night during late March when the heating system was either on or off. Data are presented only for one period during the day (Fig. 4). The air circulation/ ventilation system maintained uniform day and night temperatures. The greatest variability in temperature occurred during the day when the heating system was off and when solar radiation was increasing. The greater variation during high solar radiation was probably due to differences in light intensity caused by overhead greenhouse structural shadows. The most uniform temperatures were obtained at night when chamber heating was off (data not presented).

The computer controlled the temperature in the chambers to $\pm 1 \mathrm{C}$ of the specified set point by turning stages of heat on or off (Fig. 5). In the greenhouse compartment, the warm vented air from the six chambers maintained the temperature above the set point. When temperature was regulated based on increased solar radiation, the chamber temperature was nearly equal to the set-point temperature over $2 \mathrm{~h}$ from sunrise until the solar intensity reached $\approx 400 \mu \mathrm{pmol} \cdot \mathrm{m}^{-2} \cdot \mathrm{s}^{-1}$ (Fig. 6). During late fall to early spring, excellent environmental control was achieved within the chambers; however, day temperature was not controllable during midsummer. On warm, high-light-intensity days, without artificial shading, the air was maintained between 30 to $35 \mathrm{C}$ or close to the ambient outside temperature. When shad- 


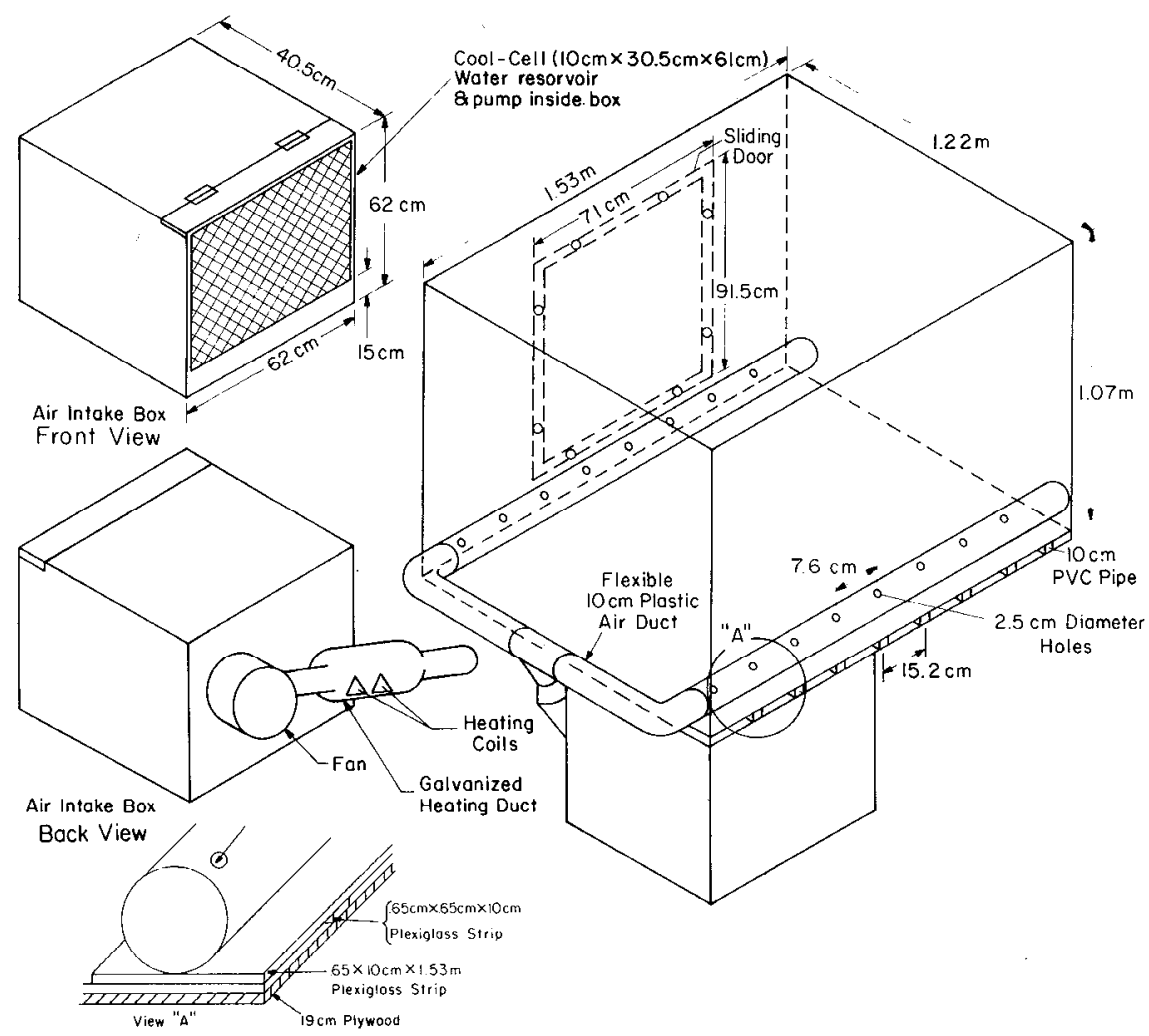

Fig. 2. Schematic view of growth chamber. ing was used on the greenhouse or growth chamber, the temperature within each chamber was reduced.

With the two-stage heating system, the maximum temperature differential possible between a chamber and the greenhouse compartment was 20C. However, this range is limited only by the heating capacity of the resistance coils. The cooling capacity, as is true of all evaporative-cooling systems, was limited by the ambient temperature and relative humidity.

During supplemental $\mathrm{CO}_{2}$ studies, $\mathrm{CO}_{2}$ was turned on manually during the light period. The concentration was maintained by regulating the $\mathrm{CO}_{2}$ flow rate from pressurized tanks into the air-intake stream. The ratio of $\mathrm{CO}_{2}$ flow rate from the tanks to the air flow rate into the chamber determined the $\mathrm{CO}_{2}$ concentration in the chamber. Samples of air from the chamber, collected in plastic bags for gas sampling, were analyzed with an Anarad infrared carbon dioxide analyzer (Santa Barbara, Calif.). A calibration curve was developed by plotting the $\mathrm{CO}_{2}$ flow rate against the $\mathrm{CO}_{2}$ concentration in the chamber. The calibration chart was used to determine the $\mathrm{CO}_{2}$ flow rate required to achieve the experimental $\mathrm{CO}_{2}$ concentration. As long as the $\mathrm{CO}_{2}$ flow rate and the air flow rate did not change, the $\mathrm{CO}_{2}$ concentration remained constant. The air with elevated $\mathrm{CO}_{2}$ levels was vented through plastic pipes to the outside of the greenhouse. However, when air movement outside the greenhouse blew toward the air inlet area, the $\mathrm{CO}_{2}$ concentration increased from 20 to $50 \mu \mathrm{l} \cdot$ liter $^{-1}$ within chambers maintained at ambient $\mathrm{CO}_{2}$ concentration. The continuously ventilated system maintained excellent control of $\mathrm{CO}_{2}$. By comparison, $\mathrm{CO}_{2}$ in closed systems requires constant monitoring with an infrared $\mathrm{CO}_{2}$ analyzer and then injection to replenish $\mathrm{CO}_{2}$. The constant injection of $\mathrm{CO}_{2}$ into the air stream, although consuming more $\mathrm{CO}_{2}$ maintained accurate concentrations of $\mathrm{CO}_{2}$ without an elaborate and expensive monitoring and injection system.

A light fixture with a $1000-\mathrm{W}$ high-pressure sodium lamp (HPS) was suspended above each chamber. The fixture could be lowered or raised to change light intensity and to create greater light uniformity across the growing area, however, placing the light fixture within $30 \mathrm{~cm}$ of the chamber caused warping of the plexiglass. Light intensity from HPS lamps, suspended $109 \mathrm{~cm}$ above the plant growing bench $(31 \mathrm{~cm}$ above the chamber floor), was measured at night with a LI-COR quantum light meter (LI-COR, Lincoln, Neb.) at 42 points on the plant growing bench. The HPS lamps provided an average supplemental photosynthetic photon flux of $\approx 200$ $\mu \mathrm{mols} \cdot \mathrm{m}^{-2} \cdot \mathrm{s}^{-1}$ with a range of 150 to 260 $\mu$ mols $\cdot \mathrm{m}^{-2} \cdot \mathrm{s}^{-1}$ (Table 1). Greater uniformity existed nearer the center of the chamber. To reflect more of the supplemental light into the chamber, a white-on-black polyethylene fabric, with the white surface facing the interior, was attached to the outside of the chamber. With a reflective material, the light

Fig. 3. Electrical wiring diagram for growth chamber. 


\section{Day: Heat On}

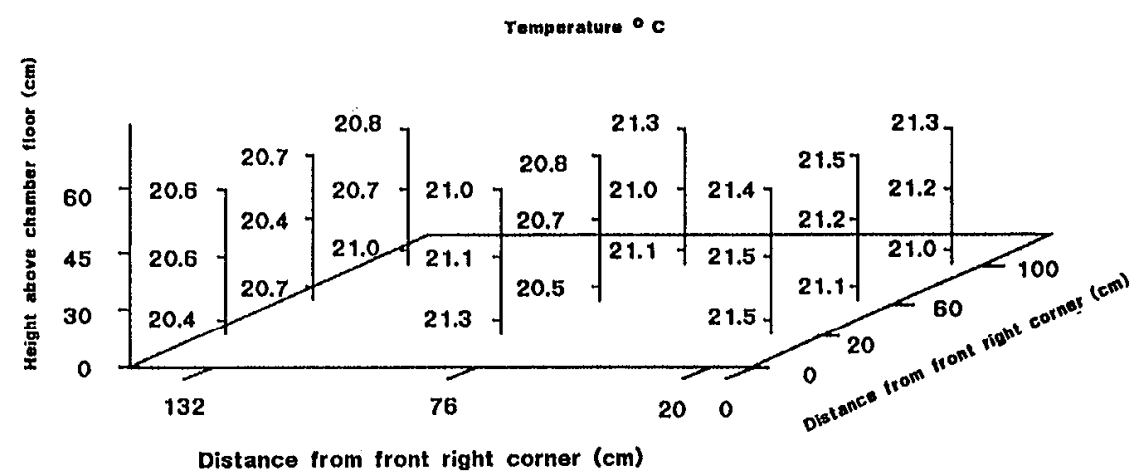

Standard error $=0.06$ at $95 \%$ confidence interval.

\section{Day: Heat Off}

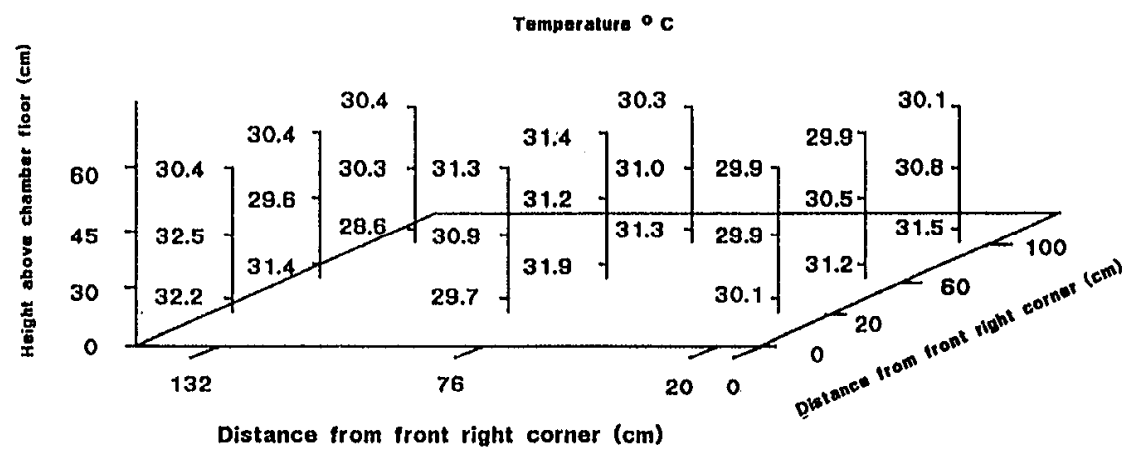

Standard error $=0.16$ at $95 \%$ confidence interval.

Fig. 4. Temperature within growth chamber at 30,45, and $60 \mathrm{~cm}$ above the chamber floor at nine positions at each height. Measurements were collected during the day: heat on and day: heat off.

\section{Stage of Heating}

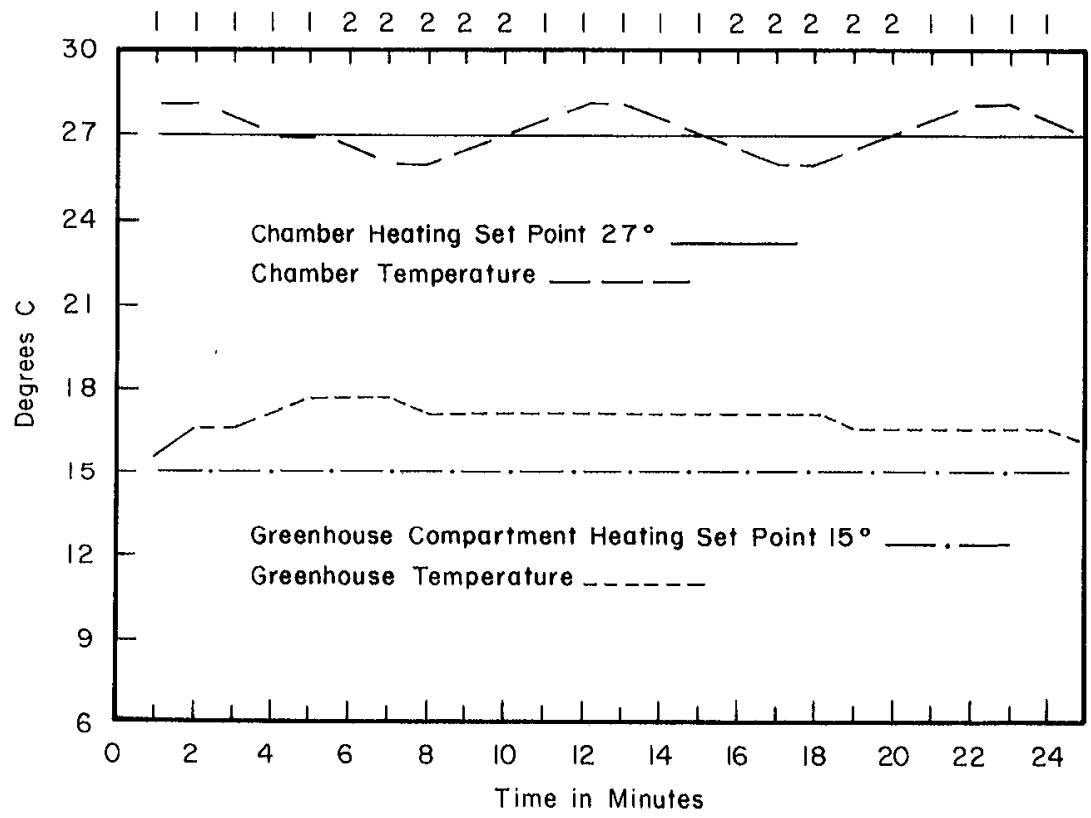

Fig. 5. Typical temperature regime maintained in chamber and greenhouse compartment on a cold but high-light-intensity day. The cooling set point for the chamber was $30 \mathrm{C}$ and the cooling set point for the greenhouse was $18 \mathrm{C}$. intensity increased to $\approx 250 \mu \mathrm{mols} \cdot \mathrm{m}^{-2} \cdot \mathrm{s}^{-1}$ with a range of 215 to $315 \mu \mathrm{mols} \cdot \mathrm{m}^{-2} \cdot \mathrm{s}^{-1}$.

A wide range of horticultural crops, including lettuce, bell pepper, and tomato transplants, were grown in the chambers. Results from experiments conducted in these chambers have been reported (Buxton and Hamilton-Kemp, 1986; Stamper, 1988).

The natural-light growth chambers are suitable for studies concerned with the complex interactions of environmental factors in the production of plants in the greenhouse. The continuous circulation/ventilation system provided excellent control of temperature throughout most of the year. Light intensity at any given time may vary between chambers because of the sun angle and the shadows cast from the structure and overhead equipment in the greenhouse and chamber. However, light variability is also a problem that affects growth in conventional greenhouse compartments. Even with this variability, the control of the environment within the chambers likely would be better than in typical large greenhouse compartments. The chambers are also well suited for work with photoperiods. Each of the chambers may be shaded independently of the others, with the additional benefit of continued air movement and cooling during the warmer periods when heat buildup may compromise results in other experimental setups.

\section{Literature Cited}

Buxton, J.W., J.N. Walker, and P.L. Cornelius. 1985. Crop response in a modified mine-air greenhouse environment. HortScience 20:222223.

Buxton, J.W. and T. Hamilton-Kemp. 1986. Changes in carbohydrates in lettuce seedlings as influenced by day and night temperature regimes. HortScience 21(3):557. (Abstr.)

Eng, Y.N., M.J. Tsujita, B. Grodzinski, and R.G. Dutton. 1983. Production of chrysanthemum cuttings under supplementary lighting and $\mathrm{CO}_{2}$ enrichment. HortScience 18:878-879.

Ewen, L.S., J.N. Walker, and J.W. Buxton. 1980. Environment in a greenhouse thermally buffered with ground-conditioned air. Trans. Amer. Soc. Agr. Eng. 23:985-993.

Hoffman, G.J. and S.L. Rawlins. 1970. Design and performance of sunlit climate chambers. Trans. Amer. Soc. Agr. Eng. 13:656-660.

Morse, R.N. and L.T. Evans. 1962. Design and development of CERES-An Australian phytotron. J. Agr. Eng. Res. 7:128-140.

Mortensen, L.M. 1982. Growth responses of some greenhouse plants to environment. III. Design and function of a growth chamber prototype. Scientia Hort. 16:57-63.

Phene, C.J., D.N. Baker, J.R. Lambert, J.E. Parsons, and J.M. McKinion. 1978. SPAR-A soilplant-atmosphere research system. Trans. Amer. Soc. Agr. Eng. 21:924-930.

Phene, C.J., D.N. Baker, J.R. Lambert, J.M. McKinion, J.E. Parsons, and J.L. Dunlap. 1979. A microprocessor-based soil plant atmosphere research system. 1979 Meeting Amer. Soc. Agr. Eng. and Can. Soc. Agr. Eng. 


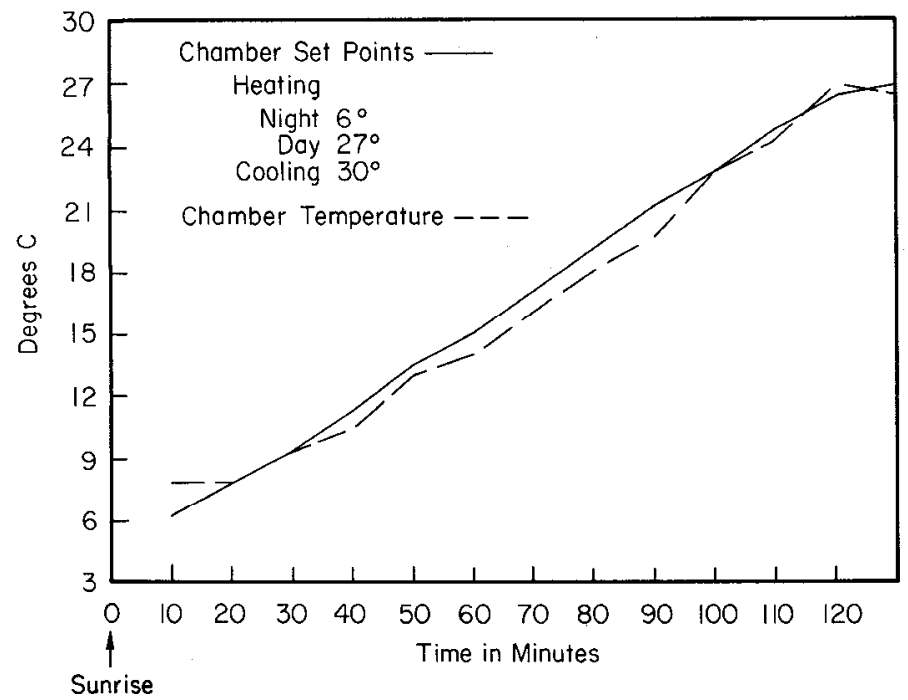

Stamper, M.A. 1988. Growth, carbohydrate content and yield of sweet pepper plants (Capsicum anпиит L.) as affected by clipping, growth regulators, temperature regimes and carbon dioxide levels. MS Thesis, Dept. of Horticulture and Landscape Architecture, Univ. of Kentucky, Lexington.

Fig. 6. Typical increase in chamber set point and corresponding chamber temperature as the light intensity increased from 0 (sunrise) to $400 \mu \mathrm{mol} \cdot \mathrm{m}^{-2} \cdot \mathrm{s}^{-1}$ on a winter morning. 